
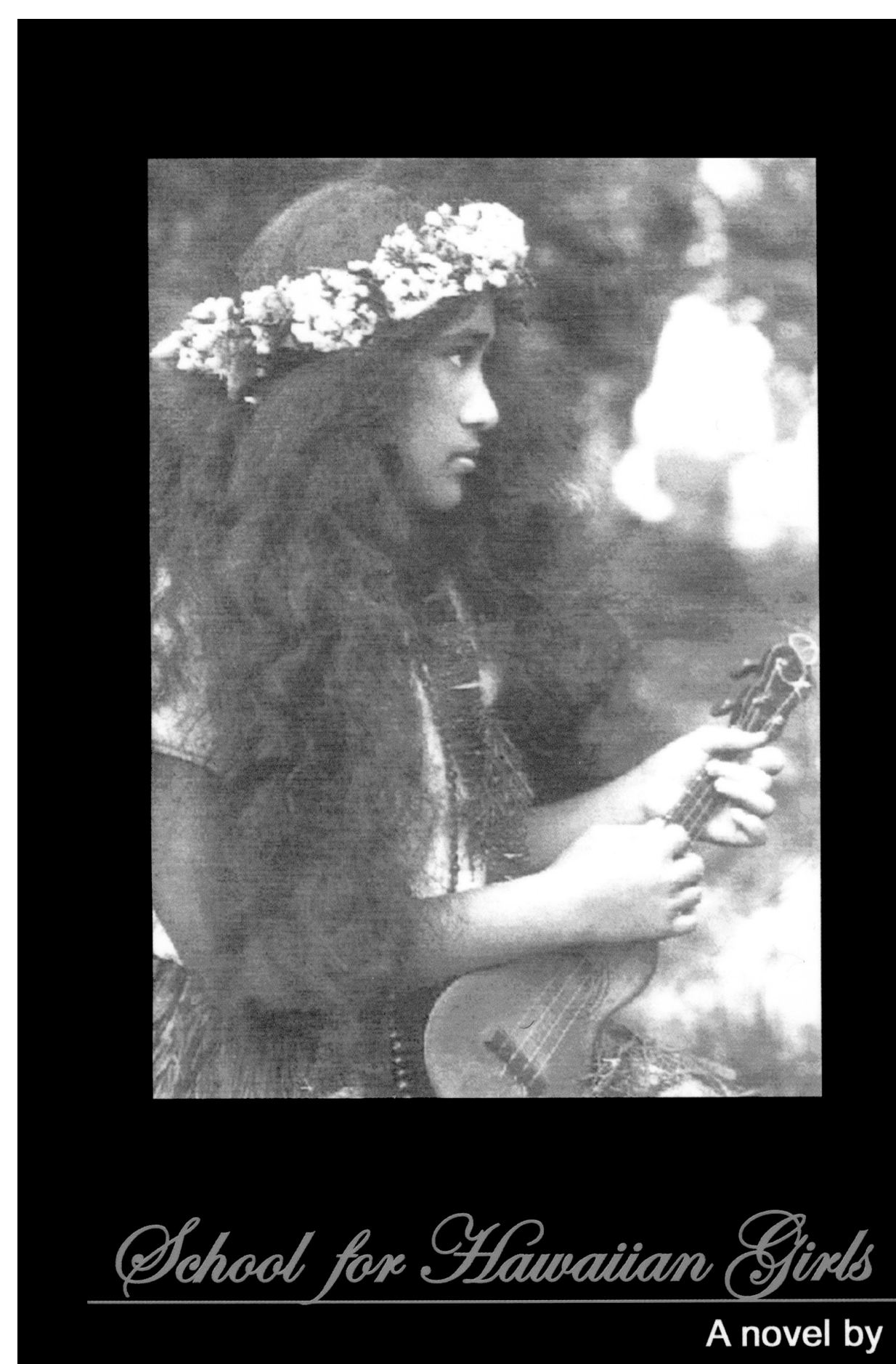

Georgia Ka'apuni McMillen 


\section{Of Blood and of the Heart: An Interview with Georgia Ka'apuni McMillen}

Cara Cilano

In June of 2004, I interviewed Georgia Ka'apuni McMillen, a Native Hawaiian writer whose work has appeared in Bamboo Ridge: The Hawaii Writers' Quarterly, and who has published a novel, School for Hawaiian Girls. Initially published in 2002 and still available through Ist Books (Bloomington, Indiana), School for Hawaiian Girls will be re-released by Permanent Press, a publishing house in New York City, in September 2005. We met at the Kula Sandalwood Restaurant, located at an elevation of approximately 3,000 feet on the slope of Haleakala on the island of Maui. The transcript of the interview that follows contains a discussion that weaves in and out of the specifics of her novel, a dialogic dynamic that allowed us to connect ideas of what Hawaiian identities are, the use of pidgin and the local literary scene, and the travails of publishing (including self-publication), to McMillen's novel and her experiences as a writer.

School for Hawaiian Girls tells the story of several generations of a single Hawaiian family, the Kaluhis, whose members are both plagued and intrigued by the memory of the murder of Lydie, sister to Sam and Bernie. With narrative planes reaching from I920s Kohala, Hawai' $i$, to I980s Honolulu, O'abu, the novel features multiple narrators, including Sam and Bernie-both belonging to the older generation of the Kalubi family-and Moani, Sam's grandniece and Bernie's granddaughter. McMillen further enriches the complexity of her narrative structure by incorporating the point of view of Sarah Christian, the daughter of a missionary, who is a contemporary of Sam and Bernie's. Central to the novel is the place named in the title: the school for Hawaiian girls that both Lydie and Bernie attend and at which Sarah teaches in the I920s. On this earlier narrative plane, Lydie figures as a magnetic character possessing a sexual and cultural

The Contemporary Pacific, Volume I7, Number 2, 387-402

(C) 2005 by University of Hawai' $i$ Press 
allure that draws other Hawaiians and the Christian children, Sarah and her brother Daniel, to her. Because of this allure, Lydie suffers a violent and tragic death that, as time passes, creates a memory that Sam and Bernie seek to repress, that Sarah ultimately embraces, and that Moani, in the novel's present (the I980s), desperately tries to uncover. In the novel's present, the school has long since been abandoned, and Moani wants to purchase the property and turn it into a hotel. Unable to cope with the memories of his boyhood, including his sister's death, which are inextricably bound to the school, Sam buys the property out from under Moani and has it demolished.

Due in large part to a decolonizing impulse, critical discussions of the literatures of Hawai'i now draw much needed attention to the fact that Hawai'i's literary tradition does not adequately reflect Hawai'i from a non-haole perspective. Critically speaking, McMillen's novel fulfills a crucial role in the contexts of Hawai'i's literary tradition by challenging what Richard Hamasaki has referred to as the body of "observer" literature that has long represented Hawai'i and its inhabitants (1993, 193). Only twenty-five years ago, Tony Quagliano, like other prominent critical voices before him such as A. Grove Day, advocated the dominance of this "observer" perspective in his promotion of a literature that has "a style informed by a variety of external, extrainsular influences, and not bound by localness either in landscape, seascape, or localness of ethnic political issues, exclusively" (1979/1980, 7). Deemed by this view as too parochial to matter, literatures about Hawai' $i$ from Hawai' $i$ (and, arguably, by Native Hawaiians) occupy a secondary or tertiary status when compared to the canon established in the nineteenth century by the likes of Melville and Twain and continued through the twentieth century by Michener and others. As Paul Lyons argued (1997), for too long this view has trumpeted "observer" literature as the valued and valuable literature about Hawai $i$.

However, School for Hawaiian Girls shrugs off the burden of anxiety, originating from the mainland, that has plagued the production of literature, particularly by non-haole writers, in Hawai'i. McMillen's novel dismisses charges of parochialism outright as it relies on the unique sites of the Big Island (Hawai'i) and O'ahu and, more significantly, draws on the singular indigenous, missionary, and plantation histories of the Hawaiian Islands. From these specificities, School conveys a story that engages broad questions of identity, memory, and belonging. Of particular interest is Sam Kalubi, one of the primary narrators, whose active consolidation of his own individual power-from marginalized Native in Kohala to hotel- 
owning tycoon in Honolulu-mirrors the American immigrant narrative. His social and economic transformation allegorizes his character development in a way that speaks to a larger (American) national imaginary. However, this allegorical trajectory plays out against the background of a novel deeply concerned with issues of Native claims to place and to familial connection, a contrast that denaturalizes Sam's transformation.

I suggest that McMillen's novel uses the American immigrant allegory only to unsettle it. This treatment also provides a subtle commentary on the status of the "local." While Rob Wilson asserted that the "local" literary scene, especially under the auspices of Bamboo Ridge, "has resisted the metropolitan assumption that writers in Hawaii 'are subordinate to the mainland," he nonetheless acknowledged how the "local" imperils Native cultural survival insofar as the term threatens to efface the differences between Natives and descendants of nineteenth-century plantation workers (1996, 318, 319). For Rodney Morales, this threat of effacement becomes most pronounced when one considers how some non-Native writers on the "local" scene "have bought into the colonial construct" of the American Dream (1998, I08). In its critical presentation of the immigrant allegory, School for Hawaiian Girls also implicitly problematizes the "local" terrain, thereby questioning the overlap between ethnic and indigenous identities in Hawai'i. By placing McMillen's novel within this many-sided context, which includes "observer" and "local" literatures, we can better achieve what Paul Lyons called a "verticalist vision" that "percolat[es] up and through and sometimes synthesiz[es] with the various sedimented layers of post-contact history (including the records left by ... missionaries, ... colonialists, [and] immigrants)" (2003, 145). When read with such a vision, School for Hawaiian Girls explores how an individual's connection to family, to the past, and to a place influences her future.

CARA CILANO: There seems to be a self-consciousness or attention drawn to a kind of femininity in School for Hawaiian Girls, most explicitly around Lydie. She becomes a woman around whom all of the men rotate, even her brother. What do you make of that?

GEORGIA KA'APUNI MCMILLEN: I see a drama between the pretty sister, Lydie, and the plain sister, Bernie. That was conscious. I liked that the pretty one takes the hit, and the plain one somehow figures out how to survive. I see Lydie as a victim. If I were to write the book again, I would make more explicit what was going on in my head, which I don't think I 
clarified to readers outside Hawai'i: that I saw Lydie as Hawaiians in general taking a big hit. What we were talking about before, regarding population statistics and explanations for them, suggests that they were doomed. The rapid decline in population was horrible; people had to forget about it to survive.

CC: Another thing with Lydie as a sort of feminized character, with the photograph on the front, it seems a way to talk about the dusky maiden stereotype, which is imposed from the outside but shown not to fit.

GKM: The imposition is powerful for a lot of reasons, one being that it sells. It's important economically to keep up the front of the Polynesian maiden, and everything that comes along with it: Islanders filled with aloha; they give and give and give. Those sorts of stereotypes are important to the tourism industry, which is chock-full of stereotypes. One of the things about these stereotypes is that they're self-imposed. There's so much put into adopting them and becoming a good Hawaiian who's really nice all the time and gives it all away. You can't be materialistic, you can't make money, you can't be successful in business or your profession. You're stuck in the ghetto of being nice and demure. It's a terrible thing to put on people. I'm not sure where it came from, but it's definitely a part of the tourism industry. And I think Hawaiians put it on each other a lot. We're not supposed to be angry about the illegal overthrow in 1893 or the annexation, which violated all canons of international law and the US Constitution. We're not supposed to demand amends or restitution or any form of recovery. That would be un-Hawaiian.

CC: I did read an interview that Haunani-Kay Trask gave to a newsletter for the women's studies program at the University of Hawai'i. She said just what you've articulated: many older Hawaiians were putting it all at a distance, saying, "That's not what it is to be Hawaiian, your getting up there and saying this, this, and this, and being demanding. That's not what being Hawaiian is all about" (1989-1990).

GKM: But it's so important for various interested parties to keep that image of just being happy with what you have. Because, if you follow through with what Trask and others say, then the solutions are very difficult. What would sovereignty look like? How would you get it? Those are huge issues, and it's not like the US is ever going to walk out of here. So, in a way, maybe some people may think it's easier to just play along with the historical whitewash. A clear-eyed reading of history is sometimes too painful. 
CC: One of the most insidious things about the tourist industry in Hawai' $i$ is that it forces Hawaiians to commodify their culture, because they don't have a lot of other employment opportunities. You have the tourist industry operating in your novel on two levels: Sam, who is sort of tycoon, and Moani, who is doing a much more grassroots sort of tourism. How do you distinguish between the sort of "gotta do it because it's the only job available" and the kind of success you portray in the novel? Did you see there being a difference in approach between uncle and niece?

GKM: I actually saw them as being similar, those two. They are very driven. They both want to be successful. They both like things. They both seek to be successful in business, an instinct that runs counter to the stereotypes about Hawaiians. I was trying with these two characters to realize in a literary context a successful Hawaiian middle class-which represents most Hawaiians, I think. I absolutely intended to defy the stereotype that Hawaiians are lazy-ukulele-strumming-do-nothings, sitting under a coconut tree all day long. I never saw this growing up. Growing up, many of the Hawaiians that I knew were in the US military. Their discipline and loyalty were a way of life. All Hawaiians I knew were middle class. Everyone worked. Everyone went to church on Sunday. The stereotype of the sexually promiscuous Hawaiian is pervasive, yet it runs so counter to the conservative modesty in dress, manners, and behavior that are part of Hawaiian culture and behavior, historically and today.

CC: In the novel, there is an emphasis on taking care of your family. Sam certainly manifests it. Yet, because he needs to control everything, his idea of taking care of his family is quite myopic. That idea of family seems to be contrasted significantly with the sort of cobbled together "nuclear"because it's not really nuclear-family that emerges at the end between the sisters, the cousin, and the kids. Were you purposefully wanting to present different ideas of family - what's working, what's not, what may be truer?

GKM: It's important to find each other. That's why information is important. Without information we can't find each other and are lost to each other. We won't realize connections to each other. So, the connection within the family in School for Hawaiian Girls could have been lost, but it wasn't. In reality though, I think connections are in fact lost. There's a loss of knowledge that two people share blood, a common ancestor. And it doesn't have to be only a blood connection; that's another theme I was interested in. It's important to find kinsmen, of blood and of the heart. 
CC: From our earlier conversation when you were talking about how the seed of this novel was born out of family secrets and being kept from memories: in a very real way, that's your experience of being in a Hawaiian family. From what you hear about ideas of 'ohana [family] and the primacy of genealogy, knowing your family and knowing the place where the family was from-this is of paramount importance. These ideas about family are at odds with one another.

GKM: They're in conflict. The tragic, true history of the Kaluhi family in School for Hawaiian Girls versus the happy-Hawaiian-'ohana stereotype. And today the 'ohana thing is really being exploited. Now, everything is 'ohana.

cC: The car dealership is 'ohana.

GKM: The car-dealership 'ohana. And it's very appealing. We're connected, the guy who fixes my car. I guess it works.

CC: In your novel, there's the character Sarah Christian, who knows and controls stories too. How does she fit into this framework of storytelling and secrets?

GKM: She's a missionary child, and like many of the missionaries' children she is sent away for education. The missionaries kept their children separated from Hawaiian children, so they only had each other as playmates. It's as if she doesn't realize that she really is a child of this place. I like her character because, on the one hand, she's awful to the girls, but at the same time there are good things that she does. She understands how important an education is to the girls. She's very clear about this.

CC: The way that you cast her relationship with her brother, Daniel, makes him a very interesting character, a wayward son. God knows what happened to him that he would turn out so bad. I don't know enough about missionary history and plantation history to know how common it was for the haole males to be philandering with the Native Hawaiians or the laborers.

GKM: I felt he was the weakest of all the characters because he's just bad. I saw no good in him. In terms of developing a well-rounded character, I don't think I ever fully realized him. The missionaries kept their children separate from Hawaiian children, and then the parents sent the children away for schooling. When the children, now adults, returned from their American educations it was very easy for them to gobble up everything 
and call it their own. There was no connection or loyalty or gratitude or respect or friendship for the sovereign nation that permitted their parents to reside here to begin with. Hawai'i was there for the taking in their view and was meant to serve their financial and political goals. Daniel is the embodiment of such selfishness. But his experience is also different from what happened historically to the missionary children. Daniel is a philanderer who takes up with a Native woman. Many white men did that, but generally not the sons and daughters of the missionary families, who ended up owning vast swaths of the land and overthrowing the kingdom to install their own government to support their dynastic control of the islands. For them, the control of land and wealth among themselves was critical. So marrying each other was important because of the land and the ensuing wealth and political power it brought, and it remained in the hands of the privileged few.

CC: There's a bit at the end, the last time we get any of Sarah's narration: she's an old woman now, in the old folks' home, and she is thinking about not wanting to have revenge on Sam anymore. She says she has the desire to go home, back to the green valleys. And this is where she wants to return to: "In the valley of the valleys, my arms about trees. Feet clutching smooth black pebbles in a stream. In the green depth of memory, I should like to weep for a long time." And then she says, "And Sam wants to go there, too." The paragraph ends, "We are, Sam and I, the same now" (225). Why are you aligning the two of them?

GKM: Because Sarah's like Sam. She realizes she's keiki o ka 'āina, child of the land. She's not Hawaiian, but she was born and raised here, and at the end of her life she understands that the life of the land flows through her veins, too: it has sustained and nourished her ungrateful heart, and she is indebted.

CC: She wants to hold on to the memory. The way that you portray Sarah at the end, there's a suggestion that she has thought a lot about Lydie over all of these decades.

GKM: She doesn't want to deny Lydie's memory and her murder anymore.

CC: And that's such an interesting thing when you're talking about the control of memory in a family. Of course, a family may not be the only ones who have access to this memory. 
GKM: Historically the missionaries were privy to what happened-but they orchestrated it. But acknowledging the truth-the political overthrow of a sovereign government, lying about the overthrow, the imprisonment of Lili'uokalani-carries the responsibility of doing something about it, making right the wrong. They have it all now. No one walks away from so much.

CC: I want to say, for the record that as you said that, "Georgia gestured toward the landscape."

GKM: No one ever gives up real estate. That's why the myth of the happy Hawaiian, who needs and wants nothing, is so important.

CC: So, in a way, Sarah really grows as a character, but she still maintains some of the same sensibilities, denying some of the things that are very threatening to her identity.

GKM: She's different. She became an educator. She doesn't have children, as opposed to the missionaries. It was important for them to have heirs, to perpetuate themselves, to continue to control.

CC: In your novel, there's a multi-perspective narrative structure that revolves around the central figure of a woman who dies, Lydie. What impulse lies behind this narrative approach?

GKM: It just seemed to make sense: I could tell a better story if I was able to assume the identities of the different characters. And then it became a choice of whose perspective to assume and of keeping the number small.

CC: While the perspectives of the individual narrators may change, more or less the place stays the same. School for Hawaiian Girls starts off with a place, the school, that becomes a fixed landscape. What do you think about that?

GKM: A sense of place is important. Hawai' $i$ is a compelling place because it's physically so beautiful. Everything happens between the mountains and the ocean, the high and the low. I'm always thinking of how to describe this to a potential reader who has never been here before.

CC: That passage we just looked at, where Sarah wants to return, is significant for all kinds of reasons: Sam has had the school demolished, so the physical structures are gone, yet Sarah wants to return to that place. She doesn't care, she doesn't know, about the school not being there anymore. She wants to return to the natural place. 
GKM: Sarah and Sam are two sides of the same coin. She wants to return to the place. He loves the place so much that he destroys it, in a sense to preserve it-to hold on to a myth before it can be changed.

CC: What is that myth?

GKM: That there was a perfect place. Everyone was happy. There was a school that cared for Hawaiian girls. That was crap. In the I920s, when the novel begins, the Hawaiian race was dying out. And the school made the girls prove their periods every month.

CC: I hadn't thought about it in those terms. Sam destroys the place because he loves it and also denies his niece who wants to buy the property to turn it into a hotel-so it's working on so many different levels, the demolition of the school.

GKM: He is so angry that if it means destroying this place that at one time meant so much to him to keep Moani from getting it, then he will do it. A little crazy in the end, maybe.

CC: Literatures of Hawai'i show a tradition of self-publication (see Wilson 2000). John Dominis Holt self-published. From the local perspective, Milton Murayama self-published All I Asking for is My Body in I975. What has been your experience self-publishing?

GKM: It's been difficult getting the publishing establishment to look at Hawai' $i$ and then at Hawaiians as subjects to be dealt with in literature. Much of the work coming out of Hawai'i that the publishing establishment finds of interest concerns immigrant-themed stories. I can see why they're interested in those stories. They fit the David vs Goliath myth; they fit the Horatio Alger, can-do American ideal: in the end, through hard work and a little luck, one will prevail. That we-Americans-are ultimately good, strong people. Whereas Native American and Hawaiian stories conflict with these literary themes. In the native context, David doesn't slay the giant; rather, Goliath kills and eats David. End of story. This truth makes the publishing establishment queasy.

CC: So this leads us to the local literary scene and whatever designations may exist to label literary production here. I think I've come across at least four: Hawai'i literature, Hawaiian literature, literatures of Hawai' $i$, and "local" literature. 
GKM: "Local" is big now-not really sure what this means. And pidgin English. Last summer there were stacks of the New Testament translated into pidgin at our largest bookstore here on Maui.

CC: If you were to shelve your books in a bookstore that had "Hawaiian literature" and "local' literature," where would you want your books?

GKM: In neither place. Ideally, I'd like to be on that large display just as you walk into the store. But if that didn't happen, then I'd like my books to be in the general literature section. One reason is economics. There's a better chance of being seen and sold if my work is displayed next to, say, the books of Native American poet and novelist Louise Erdrich. Right now, my book is relegated to the Hawaiian section, and that's usually over in the corner of the store, and I'm shelved with books on Hawaiian reefs, books on aloha shirts and cooking. School for Hawaiian Girls is set in Hawai'i, but all literature is set somewhere. I don't see why, just because it's set in Hawai' i, it has to be stuck in the corner. Why not put it in both places? The world lit section, and the Hawaiian section? The more people who see the book, the more it's purchased, and the more it's read. That's my goal: to get it in front of more readers.

CC: What other Hawaiian writers or other writers writing about Hawai' $i$ do you have on your shelf, who you think, "Yes, here we are, this generation of writers"?

GKM: Hawaiian author Sally Jo Bowman, anything she writes. She writes nonfiction and fiction, and she has somehow cracked through the conservative mainstream press to publish her articles in, for example, the airline magazines. And mind you she writes about decidedly Hawaiian issues. They're not about where to get the best cheeseburger in Lahaina or the best snorkeling spots.

CC: Eric Chock, one of the editors of Bamboo Ridge: The Hawaii Writers' Quarterly, says that he thinks the idea of literature is to recognize universal human nature, to see that you as an individual are a part of the human condition (I986). You've talked a lot about wanting your work not to be looked at as just, "Oh, it's about Hawai'i." Would you say that you subscribe to a notion similar to Chock's?

GKM: It's mundane, but one of the things I always think about is providing entertainment. Or, to put it another way, providing a good story. I'm always conscious of the reader, and I've always felt a responsibility to 
that reader to provide some kind of reading satisfaction or enjoyment. To enjoy it you would probably have to recognize something of yourself in the story, character, writing.

CC: That's exactly what Darrell Lum says. When he speaks specifically about publishing his own work and other people's work in pidgin, he says that he has felt that it's important for just your general reader to pick up Bamboo Ridge and to read, more or less, a transcription of their everyday speech. He says people need to identify with what's going on (Lum I984).

GKM: That's one of the reasons I don't emphasize writing in pidgin. I don't want the reader to have to decipher the story and dialogue. If I'm fortunate enough to have a reader buy my book, then I want to take them on an effortless journey. I don't know why; maybe I should make readers work harder. But my thought is that if someone has paid money for my book, I should try to give them something that they'll enjoy. I don't like stories where I have to stop and mouth-out the dialogue. Maybe I'm lazy. But if I have to start sounding out a word because it's written phonetically, I'm already removed from the character, the action, the place, the story. As a writer, servicing the reading experience, maintaining an uninterrupted flow, is the goal. That's the job. That's good storytelling.

CC: This gets to the idea of inclusivity or exclusivity. You're sounding as though you're prone to inclusivity.

GKM: Very much. Use of pidgin-and the phonetic spellings-stops my experience of the story, of trying to understand the character, his or her predicament. It interrupts my identification with him or her. Since the writing is set forth in a phonetic manner, I've got to stop and sound out the sentence-and I grew up speaking and hearing pidgin. There are ways of expressing unique speech patterns that don't require this sort of phonetic writing, and continue to serve the character and the story. If the goal is just to write pidgin, then fine, write sentences in pidgin. But if the goal is to write a story, then serve the story. The language serves the story, and not the other way around.

cC: Bamboo Ridge has increasingly come under fire for seeming to define the "local" in terms of a composite Asian and not at all Hawaiian. Chock answered the charges that the journal favors Asian writers by highlighting that there have not been many contributions by Hawaiians: "Perhaps 
it is true that not many Hawaiians have had the time nor inclination to study creative writing and work at developing the level of their art" (I996, I5).

GKM: I don't know what Chock meant by that quotation. As to the "local" style/culture notion, there's an attractive myth that people in Hawai'i have shared cultures and behaviors. Sure, I suppose everyone has a favorite flavor of shave ice, a favorite Kalapana hit, a favorite beach, etc. But overall, the notion of "local" history/culture buys into the historical whitewashing of Hawaiian history, and the marketing campaigns of the tourism industry-that we're all one big 'ohana. I just don't think it's true in many respects. But since we're talking about pidgin: first of all, there's no standard pidgin. Pidgin has a diversity of forms, structures, vocabulary. Also, pidgin is not synonymous with growing up in Hawai'i. Many families, schools, communities, encouraged speaking "standard" English-whatever that is.

CC: Because of the assumption that speaking pidgin means that you're not educated or that you're not speaking properly, it's been kept out of more formal settings, out of literature. So, is tracing it back to its plantation origins a way to claim an "authentic" language?

GKM: You can do that when you've achieved a certain standard of living and secured a future for your children and grandchildren. Then you can go back and lay claim to your humble roots.

cc: As you said before, immigrant narratives fit into the American mythology. Yet Hawaiians are not necessarily defining themselves as Americans. It's not the same thing, to be an indigenous person as to be an immigrant.

GKM: They're different. The immigrant story is, I think, a very good story. You come with nothing. You work really hard. You sacrifice. And, in the end, you get something: a better life for you and your children. It's the perfect sort of story arc: the hero's journey. It's classic; it's mythical. As Americans, we love it. The historical backdrop to the Native American story is different and much more complicated. To begin with, it's dubious to claim that the children and grandchildren came out ahead.

cc: Rob Wilson and Arif Dirlik talked about Bamboo Ridge being a site of resistance on the global literary scene because it refuses to be homogenized (1994). In light of what you've been saying about New York pub- 
lishing houses and wanting your own books to be shelved in the general fiction section, what do you think of this idea?

GKM: In trying to market my book myself, I've become very pragmatic. I want readers-bottom line. If that means somehow being assimilated into the rest of the bookstore, then I'm all for it. If you don't have readers, then to whom are you telling the story?

CC: Could you talk more about that? When you say you want readers, is this commercialism?

GKM: Yes, in part. More readers is only good. I don't see a downside to it. It means, first of all, that as a writer your writing gets out there. It means more sales. It means better prospects for future projects, greater distribution, greater clout. None of which I have, so I appreciate how important this is. Because I've done the self-publish route, it's very clear to me how important it is.

CC: Let's say clout's attained. Future projects: you name what you want to do-is there a project in the back of your mind?

GKM: I've completed a second book, also about Hawai'i. It would be nice if I had a publisher and I didn't have to worry about trying to publish it, market it, distribute it, convince bookstore managers to give it shelf space, find book reviewers, etc. All of that takes a huge amount of time. For example, School for Hawaiian Girls is available through Amazon.com. But Amazon has various programs by which it markets the books you see for sale on its Web page. The best program is one called "Look Inside the Book." It permits would-be buyers to actually "open" the book and read the first few pages. I personally campaigned through a series of letters to Amazon.com to convince them to include my book School for Hawaiian Girls in this great program. Thankfully, they did. But it took a lot of time. Is it commercialism? Of course. But that's not a negative; it's critical to proper distribution of the work. And without that, there can be no readers, no communication, no storytelling.

CC: It's important for me to learn, it's important for me to be able to tell my students about this. My students and I don't fully understand the idea of literature as a commodity.

GKM: That's been my education over the last three years. I had to start thinking about what it would take-assuming my book finally got shelf 
space at the bookstore-to get the would-be book buyer to pull the book off the shelf, open it, and start reading.

CC: So, literary production is market driven?

GKM: With respect to the publishing industry, yes. I understand that it's getting worse, but then there are the small presses around. Frequently, the large presses and the good small presses won't look at anything unless it's "agent-ed." So, you need an agent, and an agent has to make a living. They've got to be able to find properties that they can sell. Already, you're whittling down manuscripts. That's why immigrant stories sell-because they make people feel good. They are good stories: the classic hero myth. People understand that. It's safe. To an extent, writers have to think of their work as a commodity. I'm not saying we must be slaves to the market. But if the idea is ultimately telling a good story, then you need a reader to complete the circle. To get the reader you need the publisher, a method to distribute, some kind of marketing. You need to think these things through. How does one convince the would-be book buyer to pull the book off the shelf? Open it? Read the first page? If the writing is dead on the first page, why would they finish reading the chapter? Buy the book? This is especially true for the unknown author. Whereas if the reader is grappling with a difficult opening page, but the author is famous, then the reader is more likely to give the benefit of the doubt to the author and stay with the work a little longer, maybe even buy the book.

cc: Have you found a community of writers here like you had in New York?

GKM: No. In New York I attended the Writers' Workshop for two years. Initially it was helpful. Otherwise, I find it helpful to listen to interviews with other artists-not necessarily writers, but anyone talking about the creative process. I remember listening to an interview with jazz artist Wynton Marsalis. He said that he had learned to ask himself very good questions, questions he'd be willing to live with for a few years-in the musical context. I also find it helpful to study the writing of other fiction writers. I also like to read the local papers, small publications. There are wonderful story ideas there.

CC: So inspiration can come from anything?

GKM: Yes. 
I GRATEFULLY ACKNOWLEDGE the assistance provided to me by the University of North Carolina Wilmington and the funds made available to me through the Charles L Cahill Award.

\section{References}

Chock, Eric

I986 On Local Literature. In The Best of Bamboo Ridge: The Hawaii Writers' Quarterly, edited by Eric Chock and Darrell H Y Lum, 6-9. Honolulu: Bamboo Ridge Press.

I996 The Neocolonization of Bamboo Ridge: Repositioning Bamboo Ridge and Local Literature in the I990s. In Bamboo Ridge: The Hawaii Writers' Quarterly 69 (Spring): I I-25.

Hamasaki, Richard

I993 Mountains in the Sea: The Emergence of Contemporary Hawaiian Poetry in English. In Readings in Pacific Literature, edited by Paul Sharrad, I90-207. Wollongong, Australia: University of Wollongong Printery.

Lum, Darrell H Y

I984 What is Local Literature? Part I. In Literary Arts Hawaii Newsletter Lyons, Paul 73 (March): 9 .

I997 Pacific Scholarship, Literary Criticism, and Touristic Desire: The Specter of A. Grove Day. boundary 224 (Summer): 47-78.

2003 Reading the Literatures of Hawai'i Under an "Americanist" Rubric. In Beyond the Borders: American Literature and Post-Colonial Theory, edited by Deborah Madsen, I35-I47. London: Pluto.

McMillen, Georgia Ka'apuni

2002 School for Hawaiian Girls. Bloomington, IN: Ist Books. Reprinted in 2005 by Permanent Press, New York.

Morales, Rodney

I998 Literature. In Multicultural Hawai' $i$ : The Fabric of a Multiethnic Society, edited by Michael Haas, I07-I29. New York: Garland.

Murayama, Milton

I975 All I Asking For Is My Body. San Francisco: Supa Press. Reprinted in I 988 by University of Hawai'i Press, Honolulu.

Quagliano, Tony

I979/I980 Notes on Some Dangers in the Notion of Regionalism in Literature. HLAC (Hawai'i Literary Arts Council) Newsletter 7-8.

Trask, Haunani-Kay

I989-r990 The Feminization of Hawai'i: Occupation of a Nation: A Dialogue between Haunani-Kay Trask and Lillian Robinson. Interview by 
Kathy E Ferguson and April Wilson South. Voices: Women's Studies Newsletter (University of Hawai'i Women's Studies Program) 3 (Winter): 4-I6.

Wilson, Rob

I996 Goodbye Paradise: Global/Localism in the American Pacific. In Global/ Local: Cultural Production and the Transnational Imaginary, edited by Rob Wilson and Wimal Dissanayake, 3I2-336. Durham, NC: Duke University Press.

2000 Reimagining the American Pacific: From South Pacific to Bamboo Ridge and Beyond. Durham: Duke University Press.

Wilson, Rob, and Arif Dirlik

I994 Introduction: Asia/Pacific as Space of Cultural Production. In bound$\operatorname{ary} 22 \mathrm{I}(\mathrm{I})$ : I-I4. 